MIDAS

Museus e estudos interdisciplinares

$1 \mid 2013$

Varia

\title{
Documento e musealização: entretecendo
} conceitos

Document and musealisation: interweaving concepts

\section{Maria Lucia de Niemeyer Matheus Loureiro e José Mauro Matheus Loureiro}

\section{(apenEdition}

\section{Journals}

\section{Edição electrónica}

URL: http://journals.openedition.org/midas/78

DOI: $10.4000 /$ midas.78

ISSN: 2182-9543

\section{Editora:}

Alice Semedo, Paulo Simões Rodrigues, Pedro Casaleiro, Raquel Henriques da Silva, Ana Carvalho

Refêrencia eletrónica

Maria Lucia de Niemeyer Matheus Loureiro e José Mauro Matheus Loureiro, « Documento e musealização: entretecendo conceitos », MIDAS [Online], 1 | 2013, posto online no dia 01 abril 2013 consultado no dia 19 abril 2019. URL : http://journals.openedition.org/midas/78 ; DOI : 10.4000/ midas.78

Este documento foi criado de forma automática no dia 19 Abril 2019.

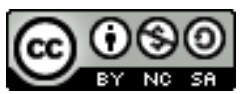

Midas is licensed under a Creative Commons Attribution-NonCommercial-ShareAlike 3.0 International License 


\title{
Documento e musealização: entretecendo conceitos ${ }^{1}$
}

\author{
Document and musealisation: interweaving concepts \\ Maria Lucia de Niemeyer Matheus Loureiro e José Mauro Matheus \\ Loureiro
}

\section{Introdução}

1 Na obra intitulada "O que é filosofia?", Deleuze e Guattari afirmam que conceitos são construções ou criações. Eles "não nos esperam inteiramente feitos, como corpos celestes. Não há céu para os conceitos. Eles devem ser inventados, fabricados ou antes criados, e não seriam nada sem a assinatura daqueles que os criam". Todo conceito "tem componentes e se define por eles", são dotados de um "contorno irregular" e definidos "pela cifra de seus componentes", mantendo necessariamente uma relação estreita com problemas "sem os quais não teriam sentido" (Deleuze e Guattari 1992, 13, 27).

2 Conceitos seriam, assim, sempre abertos e provisórios, pois, quanto mais são criados, mais se põem, e por isso mesmo são passíveis de ser "substituídos por outros... sob a condição de novos problemas e de um outro plano" (Deleuze e Guattari 1992, 40).

3 O texto que se segue aborda o conceito de musealização como processo (ou conjunto de processos) por meio dos quais alguns objetos são privados de sua função original e, uma vez revestidos de novos significados, adquirem a função de documento. Para enfatizar seu caráter informacional, são apresentadas reflexões em torno da noção de documento ao longo do século XX, com ênfase em Paul Otlet, cuja contribuição pioneira contribuiu para a ampliação do conceito para além dos textos escritos e inspirou inúmeros autores que retomaram sua obra e aprofundaram suas reflexões, contribuindo para a construção do que Niels Windfeld Lund (2009) denominou "Teoria Profissional do Documento".

4 Em virtude de seu caráter multidimensional, o processo de musealização é de difícil apreensão em sua totalidade. Sua dimensão informacional, entretanto, é enfatizada por inúmeros autores, entre os quais Ulpiano Bezerra de Meneses (1992, 111), para quem o 
eixo da musealização é o "processo de transformação do objeto em documento", e Ivo Maroevic $(1998,74)$, que associa o amadurecimento teórico da disciplina Museologia ao reconhecimento do valor informativo do objeto e, consequentemente, de seu estatuto de documento.

Na reflexão sobre o objeto musealizado como documento está implícita, portanto, uma concepção ampla de documento, tema do tópico que se segue.

\title{
Apontamentos sobre o conceito de documento
}

Derivado do latim docere, o termo documento foi, na História, amplamente associado ao testemunho escrito, conforme a tradição da escola positivista. A utilização exclusiva das fontes textuais seria, no entanto, questionada a partir de 1929 pelos historiadores da Escola dos Annales:

\begin{abstract}
A história faz-se com documentos escritos, sem dúvida. Quando estes existem. Mas pode fazer-se, deve fazer-se sem documentos escritos, quando não existem. Com tudo o que a habilidade do historiador lhe permitir utilizar para fabricar o seu mel, na falta das flores habituais. Logo, com palavras. Signos. Paisagens e telhas. Com as formas do campo e das ervas daninhas. Com os eclipses da lua e a atrelagem dos cavalos de tiro. Com os exames de pedras feitos pelos geólogos e com as análises de metais feitas pelos químicos. Numa palavra, com tudo o que, pertencendo ao homem, depende do homem, serve o homem, exprime o homem, depende do homem, demonstra a presença, a atividade, os gostos e as maneiras de ser do homem (Febvre apud Le Goff 2003, 530).
\end{abstract}

7 Na década de 1960, Samaran (apud Le Goff 2003, 531) afirma que "não há história sem documentos", acrescentando, porém, que o termo "documento" deveria ser compreendido "no sentido mais amplo, documento escrito, ilustrado, transmitido pelo som, a imagem, ou de qualquer outra maneira".

8 A reflexão em torno da noção de documento encontra espaço também no âmbito das Ciências da Informação, onde duas correntes marcam a compreensão do conceito ao longo do século XX: uma corrente pragmática, que ressalta o caráter intencional do documento e o limita aos registros gráficos (sobretudo textuais), e uma corrente funcionalista, atrelada à sua função documental e informativa, inaugurada pelo advogado belga Paul Otlet e a documentalista francesa Suzanne Briet (Smit 2008).

Visto como um objeto concreto, o documento seria o meio pelo qual "a informação, o conteúdo, ganham forma no plano comunicacional" e simultaneamente "o suporte que possibilita a sua circulação". As bases para as reflexões em torno da noção de documento teriam sido estabelecidas por Otlet - que admitiu "suportes outros que não o papel e unidades de informação menores que o livro" - e complementadas por Suzane Briet, que incluiria posteriormente os seres vivos (Couzinet 2009).

Para Otlet, a noção de documento aplica-se a tudo aquilo que for passível "de guarda e preservação, pois é representante de alguma ação humana ou de algum detalhe da natureza" (Smit 2008). Michael Buckland (1991) enfatiza o uso por Otlet da expressão "unidade documentária" como "termo genérico para denotar coisas informativas", incluindo, ao lado de textos, objetos naturais, artefatos e "objetos portadores de vestígios de atividades humanas". Embora não tenha explorado a noção de documento em sua totalidade, Otlet promoveu uma considerável ampliação ao considerar todo e qualquer 
objeto produzido pelo homem, ou seja, dotado de uma "intencionalidade para um determinado uso" (Rabello 2009, 178-179).

11 Em seu "Tratado de Documentação", o autor usa a palavra "livro" para se referir aos manuscritos e impressos que constituiriam a "memória materializada da humanidade". Ao lado dos livros "propriamente ditos", entretanto, haveria "uma multiplicidade de documentos de toda espécie que não foram publicados nem são destinados a sê-lo" (Otlet 1934, 43, tradução nossa). O termo genérico "biblion" designa, assim, uma "unidade intelectual e abstrata" passível de ser recuperada concretamente. O estatuto de documento é estendido às coisas, uma vez que "a intenção presidiu a reunião (coleta) e sua utilização para estudo, ensino e pesquisa" (Otlet 1934, 356).

O "objeto de museu" é especificamente incluído por Otlet $(1934,216-217)$ no âmbito de uma documentação ampliada, ao lado de inventos mais ou menos recentes como o telégrafo, o rádio, a televisão e os discos, designados provisoriamente como "substitutos do livro". Os objetos são classificados em "cinco grandes espécies", que compreenderiam: (...) os objetos naturais (...), os objetos artificiais criados pelo homem para suas necessidades, (...) os objetos portadores de traços humanos que servem à interpretação $\mathrm{e}$ têm significado, os objetos demonstrativos, igualmente criados pelo homem, mas para representar e demonstrar noções (...) e os objetos de arte (Otlet 1934, 217).

Tais reflexões inspiraram a documentalista francesa Suzanne Briet que recolocou, “após a Segunda Guerra Mundial, muitos dos princípios estabelecidos por ele, em especial por meio da obra clássica 'Qu'est-ce que la documentation?', publicada em 1951" (Ortega e Lara 2009 , 124). Otlet e Briet "trabalharam a noção de documento a partir de novas possibilidades, o que abriu precedentes para pensá-los como informação fixada em diferentes tipos de suporte e a partir do seu papel social" (Murguia 2011, 45).

Enfatizando que a definição oficial de documento emanada da Union Française des Organismes de Documentation ${ }^{2}$ - "toda base de conhecimento fixada materialmente e suscetível de ser utilizada para consulta, estudo ou prova" - teria sido posta em cheque por linguistas e filósofos, Briet redefine documento como "todo índice concreto ou simbólico, conservado ou registrado com os fins de representar, reconstituir ou provar um fenômeno físico ou intelectual", acrescentando:

Uma estrela é um documento? Um seixo levado pela torrente é um documento? Um animal vivo é um documento? Não. Mas são documentos as fotografias e os catálogos de estrelas, as pedras em um museu de mineralogia, os animais catalogados e expostos em um Zôo (Briet 1951, 7, tradução nossa).

Os aspectos tecnológicos de uma época marcada por "transmissões multiplicadas e aceleradas" são ressaltados por Briet, que destaca a "fertilidade documentária" resultante, exemplificando-a com uma cadeia de eventos iniciado pela captura de um animal (um antílope, visto como documento) e sua chegada em um jardim zoológico: o animal é capturado na África e levado para o "Jardin des Plantes" de Paris, torna-se tema de notícias em jornais e rádio, e objeto de comunicações científicas. É exposto em uma jaula no zôo e, depois de morto, naturalizado e exposto em um museu. É filmado, tem seu rugido registrado em disco, é representado em ilustrações científicas posteriormente incluídas em monografias e enciclopédias. As obras são catalogadas em uma biblioteca, copiadas, selecionadas, descritas, traduzidas... "O antílope catalogado", afirma a autora, "é um documento primário e os demais são documentos secundários ou derivados" (Briet 1951, 7-8, tradução nossa). 
17 Para Michael Buckland (1997), embora as regras de Briet para determinar quando um objeto se torna documento não sejam explícitas, é possível inferir, a partir de seu texto, as seguintes condições:

1) Há materialidade: apenas objetos e sinais físicos; 2) Há intencionalidade: pretende-se que o objeto seja tratado como evidência; 3) Os objetos devem ser processados: eles devem ser transformados em documentos; e 4) Há uma atitude fenomenológica: o objeto é percebido como documento (Buckland 1997, tradução nossa).

Após ter sido colocado como noção fundamental pelos pioneiros da Documentação, o conceito de documento seria retomado por Jean Meyriat em um artigo intitulado "Document, documentation, documentologie", cuja influência é atestada por Viviane Couzinet, que o considera o "texto fundador" da noção de documento ao propor "uma ciência específica, a ciência do documento ou documentologia" (Couzinet 2009, 13).

A subdivisão proposta por Jean Meyriat entre "documento por intenção" e "documento por atribuição" inscreve-se, assim, na mesma trajetória iniciada por Otlet na década de 1930 (Couzinet 2004, 19). Ao definir documento como "um objeto que dá suporte à informação, serve para comunicar e é durável", ressalta a intervenção de duas noções inseparáveis: "uma de natureza material (o objeto que serve de suporte), outra conceitual (o conteúdo da comunicação, ou seja, a informação)" (Meyriat 1981, p. 51, tradução nossa). Assim como Otlet e Briet, sua concepção de documento ultrapassa o escrito:

Todo objeto pode ser carregado de certa função. Por essa razão, a noção de "documento" é muito mais larga que a de "escrito". Os documentos escritos constituem um caso privilegiado, porque a escrita é o meio mais comumente utilizado para comunicar uma mensagem (Meyriat 1981, 52, tradução nossa).

Para o autor, todo objeto pode ser tornado documento, o que não equivale a afirmar que todo objeto tem por função dar suporte à informação, mas que esta pode ser uma de suas funções.

Essa primeira distinção sugere que o documento tem uma dupla origem possível. Se não foi criado como tal, o objeto pode ser transformado em documento por aquele que busca a informação, ou seja, que lhe reconhece um significado, erigindo-o assim como suporte de mensagem (Meyriat 1981, 52, tradução nossa).

21 Emissor e receptor da mensagem estariam "habilitados a lhe dar um significado", mas "a vontade do emissor não é suficiente". Para que um objeto seja considerado como um documento, é essencial que haja "a vontade de obter uma informação", ainda que a intenção de seu criador tenha sido outra. o documento não seria, portanto, um dado, "mas o produto de uma vontade, a de informar ou a de se informar - sendo que pelo menos o segundo é sempre necessário". Caso a vontade de informar não encontre resposta no receptor, a informação "permanece virtual". O objeto que lhe serve de suporte não é ainda um documento, mas poderá vir a sê-lo posteriormente, se for ativado por uma nova questão (Meyriat 1981, 52-53, tradução nossa).

o que faz com que um objeto seja considerado como documento não é, portanto, "uma carga latente, definida, pronta para ser extraída, como o sumo de um limão". Embora objetos criados com a função específica de documentar - ou "objetos de nascença" sejam encontrados em algumas sociedades, "todo e qualquer objeto é passível de ser utilizado como documento" (Meneses 1998, 95).

Documento pode ser definido como "um objeto informacional visível ou tangível e dotado de uma dupla independência em relação ao tempo", a saber, a sincronia e a estabilidade. A 
primeira relaciona-se à "independência interna da mensagem que não é mais uma seqüência linear de eventos, mas uma justaposição multidimensional de traços"; enquanto a segunda diz respeito à "independência global do objeto informacional que não é mais um evento inscrito no fluxo do tempo, mas um suporte material do traço que pode ser conservado, transportado, reproduzido" (Escarpit 1976, 120, tradução nossa).

Do ponto de vista da evolução semântica, pode ser "instrumento de cultura, instrumento de conhecimento e fixação da realidade, mensagem no processo de informação documental e fonte de conhecimento científico" (López Yepes 1997, tradução nossa). A invenção do documento permitiria ao ser humano reproduzir fragmentos da realidade, e, por meio de sua permanência além do espaço e do tempo, voltar a utilizá-los como fonte de informação para a obtenção de novos conhecimentos. O documento constitui-se, assim, um instrumento precioso que...

...possibilita a geração de novas mensagens ou a recuperação de antigas. Por isso criamos documentos incessantemente constituindo um universo de novas possibilidades para decifrar os enigmas de nosso entorno, e eles são a memória viva do passado e do futuro, essência potencial e atualizável quando tratamos de interpretar ou de iluminar os acontecimentos cotidianos, fonte primitiva de informação para nova informação. (...) A vida se perpetua em documentos e nos traços que, sobre eles, deixaram as pessoas que nos precederam no tempo. Por outro lado, o documento também aprisiona o tempo e torna viável, por essa razão, a consciência histórica. (López Yepes 1997, 13-14, tradução nossa)

López Yepes (1997) estabelece uma distinção entre uma concepção estática e uma concepção dinâmica do documento, recorrendo, para ilustrá-las, a uma pintura integrante do acervo de um museu - o quadro "Las Lanzas" ("As Lanças") de Velázquez. A obra...

...admite, ao menos, duas posturas no momento de sua contemplação: uma contemplação estética ou uma contemplação documental, quando o quadro se converte em fonte de informação para conhecer como se vestiam ou iam armados os soldados da época. A partir daí o museu é alternativamente espaço de fruição estética e de documentação. Esta última é a verdadeira concepção de documento (López Yepes 1997, 16, tradução nossa).

A partir dessa "concepção essencialmente informativa" o documento pode ser visto como:

...um suporte que contém uma informação potencialmente transmissível no espaço e no tempo e atualizável para alcançar um novo conhecimento ou tomar uma decisão (...). O documento como fonte de informação parece, pois, dormir placidamente até o momento e o lugar determinado em que nos resolva uma dúvida (López Yepes 1997, 16, tradução nossa).

Enquanto "portador e transmissor de mensagens registradas e recuperáveis", o documento "se projeta no futuro com vistas à sua comunicação e utilização em um momento que desconhecemos" (López Yepes 1997, 16-17, tradução nossa).

Sejam ou não produto humano, os objetos de museu, para Caballero Zoreda (1986, 3), "humanizam-se com o contato e leitura humana", convertendo-se em "documentos plenos de signos e de dados que podemos compreender e que têm significado para nós".

\section{O objeto musealizado como documento}

Refletir sobre o objeto musealizado implica em considerar o conceito de musealização. A palavra teria sido introduzida no campo da Museologia por Zbynek Stránský que, como 
observa Baraçal $(2008,72)$, atribuiu grande atenção às questões terminológicas. É o próprio Stránský (citado por Baraçal 2008, 64) quem assume a autoria do termo, "inicialmente trabalhado por ele e por Wilhelm Enennbach, no início dos anos 70, junto com a palavra musealidade, como um processo de adquirir musealidade".

Peter van Mensch nota que o conceito de "musealidade" foi redefinido pelo próprio Stránský ao longo dos anos. Inicialmente, ele teria associado o campo de interesse da museologia ao "reconhecimento do objeto como fonte primária de conhecimento" 3 e, cerca de uma década mais tarde, afirmaria que a tarefa da disciplina era "perceber e identificar documentos que, em diferentes aspectos representem certos valores sociais" Tal "valor documentário" corresponderia à idéia de musealidade (Mensch 1992).

31 Conforme Klaus Schreiner (1980, 39), Stránský define o museu como uma "instituição documentária que acumula, preserva e comunica testemunhos autênticos da realidade objetiva". Identificada como o objeto de estudo da Museologia, a musealidade, por sua vez, é definida como o "valor documentário específico dos objetos concretos e perceptíveis da natureza e sociedade, o valor de evidência autêntica da realidade".

32 Anos mais tarde, Stránský (1985, 97-98) afirma que a natureza do objeto de museu viria de "certa relação entre homem e realidade" à qual denomina "musealidade", e cuja especificidade seria "motivada por um esforço para preservar, contra a natureza da mudança e extinção, objetos da realidade natural e social" passíveis de representar valores cuja conservação seja de interesse para a sociedade. Objetos de museu (musealia) seriam "ontologicamente coincidentes com o objeto em geral, mas do ponto de vista semântico têm uma nova função, (...) a de autênticos testemunhos, documentos e/ou evidências de fatos naturais e sociais". Partindo da premissa de que o museu oferece "um modo específico de apreensão da realidade", Stránský $(1987,289)$ redefinirá posteriormente a "musealidade" como "o caráter museal das coisas"6.

33 Ao buscar uma definição (ainda que aberta e provisória) para o processo de musealização a partir de uma perspetiva informacional, é essencial reconhecer a irregularidade de seu contorno, identificar seus componentes e os problemas aos quais remete. Admitindo a musealização como estratégia de preservação (que deve ser compreendida em sentido amplo: preservação física e preservação das informações, o que pressupõe o acesso) e como processo (ou conjunto de processos) de caráter necessariamente seletivo (musealizar implica em selecionar), podemos dizer que:

... a musealização consiste em um conjunto de processos seletivos de caráter infocomunicacional baseados na agregação de valores a coisas de diferentes naturezas às quais é atribuída a função de documento, e que por esse motivo tornam-se objeto de preservação e divulgação. Tais processos, que têm no museu seu caso privilegiado, exprimem na prática a crença na possibilidade de constituição de uma síntese a partir da seleção, ordenação e classificação de elementos que, reunidos em um sistema coerente, representarão uma realidade necessariamente maior e mais complexa (Loureiro 2011, 2-3).

O conceito de objeto musealizado compreende virtualmente elementos de diferentes naturezas, oriundos de diferentes domínios: ele pode ser "artificial ou natural, morto ou vivo, humano ou animal, orgânico ou inorgânico, único ou representativo" (Alberti 2005, 561-562, tradução nossa). Objetos de museu são "pedaços do mundo físico" que se definem pelo valor cultural que lhes é agregado (Pearce 1992, 5, tradução nossa), o que remete a um ato da seleção. Seu "valor documentário" se expressa em um "eixo temporal" uma vez que, ao longo de sua existência, "acumulam os traços do tempo e eventos em sua 
estrutura material e formal" e simultaneamente, "por sua estrutura material e forma transfere os valores preservados para o futuro" (Maroevic 2004, 25, tradução nossa).

Abordando o museu como ambiente de informação e contexto documentário, Ceravolo e Tálamo $(2007,7)$ destacam o estatuto de documento adquirido pelo objeto, cujo significado é fundado na "correlação de dados que vão da materialidade (...) às intenç̃ôes socioculturais". Entretanto, por se tratar de um artefato, ou seja, de "uma produção do homem inserida numa conjuntura social", é impossível desvincular "a combinação de suporte e conteúdo da forma e função".

O ato de transformar "objetos do cotidiano em documentos é intencional", e contribui para a criação de uma "categoria temporária e circunstancial" de documentos. O documento é, assim, "uma representação, um signo, isto é, uma abstração temporária e circunstancial do objeto natural ou acidental, constituído de essência (forma ou forma/ conteúdo intelectual), selecionado do universo social para testemunhar uma ação cultural" (Dodebei 1997, 174-175).

Uma das questões cruciais (e sem dúvida a que rende ao museu as críticas mais ferozes) diz respeito ao deslocamento (físico e simbólico) dos objetos de seu contexto primário para um contexto segundo (e artificial), a coleção, onde assume uma função documental e se torna representante da realidade da qual foi afastado. Nessa passagem, o objeto perde seu espaço e funções originais: ele é re-contextualizado e re-significado, desprende-se de uma realidade imediata para remeter e evocar realidades ausentes ${ }^{7}$.

Produzida pela "seleção e reagrupamento de objetos suscetíveis de apresentar interesse estético, científico, cultural ou simplesmente informativo", a coleção não é um mero "inventário de objetos heteróclitos", uma vez que é integrada por objetos assemelhados ou complementares. Caracteriza-se por "certa homogeneidade e certa coerência, que dão sentidos aos objetos que a integram", e pode ser vista como um "espaço artificial e abstrato onde os objetos se posicionam uns em relação aos outros" (Metzger 2006, 49, tradução nossa).

Coleções desempenham três funções principais: a primeira é uma "função de conservação", na medida em que "todo objeto não preservado e não registrado é condenado à inacessibilidade e à perda". Essa observação vale não apenas para objetos tangíveis, "que desaparecem da memória dos homens e sofrem os estragos do tempo", mas também para os intangíveis, como "dados, enunciados, imagens e sons". A segunda função relaciona-se ao acesso, pois uma coleção é "concebida para permitir ou, ao menos, facilitar o acesso aos objetos que a compõem". Deve ser dotada de uma "dupla acessibilidade" simultaneamente física e intelectual; deve ser não apenas acessível em seu conjunto, mas também "propor os meios para o alcance e apreensão de seus objetos". A terceira função relaciona-se à identificação e à descoberta, pois "o usuário de uma coleção que não foi construída por ele próprio ou que ele não frequenta regularmente, tem acesso frequentemente por acaso, a objetos cuja existência ignorava". Uma das grandes questões envolvidas na gestão das coleções seria, assim, "a busca do justo equilíbrio entre boa conservação e boa acessibilidade. Pois quanto maior o acesso à coleção mais rápida é sua degradação. É por isso que as coleções patrimoniais são de acesso muito mais limitado que outras" (Metzger 2006, 49, tradução nossa).

A noção de coleção implica em seleção e preservação, remete a um espaço delimitado e a uma audiência. Para Krzysztof Pomian, trata-se de um 
... conjunto de objetos naturais ou artificiais, mantidos temporária ou definitivamente fora do circuito de atividades econômicas, sujeitas a uma proteção especial, num local fechado preparado para esse fim e expostos ao olhar do público... (Pomian 1984, 53). invisível, as coleções seriam integradas por "semióforos", objetos "dotados de um significado" que não são manipulados nem consumidos, mas expostos ao olhar (Pomian 1984, 71). coleção: trata-se de um artefato (Pearce 1992), ou uma expressão do "amor ao absoluto", que pressupõe a apropriação de uma parte do mundo pelo homem com o intuito de dominá-lo (Moles 1981, 14). É um todo orgânico que, assim como os elementos que a integram, desempenha função documental:

Uma coleção de museu é um conjunto multidimensional de objetos de museu. Mais frequentemente, funciona como uma unidade composta por objetos individuais, acumulando e transferindo o valor documentário do objeto de museu para um nível mais alto. A coleção não é a mera soma de objetos de museu, porque por sua própria natureza pode ser ampliada ou mesmo reduzida em escopo. É um organismo vivo que, em certas situações, (...) pode desempenhar o papel de um objeto de museu e, vista como um todo, tem o significado e o valor de um documento. Nesse caso, os valores documentários dos objetos individuais são somados ao valor da coleção como um todo (Maroevic 2004, 26, tradução nossa).

Referindo-se em particular às coleções etnográficas, Beltrão (2003) ressalta que são constituídas por testemunhos materiais dotados de valor documental, histórico e simbólico, e que seu valor é reconhecido

...não apenas pelos estudiosos, mas pelos produtores dos artefatos, na medida em que é possível repassar às novas gerações, através da socialização, o saber específico que diz respeito à fabricação das peças, saber este que não se resume ao saber técnico, mas é referenciado pelas origens mitológicas e cosmológicas dos objetos (Beltrão 2003).

Elizabet Orna e Charles Pettit (citados por Buckland 1991) advertem que "no estágio inicial, os próprios objetos são os únicos repositórios de informação". Buckland (1991) ressalta que a insistência em um conceito estreito de documento que não considere a diversidade de objetos "potencialmente informativos" contraria o senso comum, e questiona: "Quanto saberíamos sobre dinossauros se nenhum fóssil de dinossauro fosse encontrado?" (Buckland 1991).

Neste ponto, retornamos às reflexões de Meyriat (1981), que reconhece nos objetos musealizados a condição de "documentos por atribuição".

Os esqueletos do Museu de História Natural conservam e fornecem informações sobre a fauna da era quaternária; os trajes camponeses do Museu de Artes e Tradições Populares, sobre os modos de vida e os costumes da França rural no século XVIII, mas também sobre técnicas de tecelagem, sobre o clima de diversas regiões à época... (...) Todo objeto pode assim ser tornado documento. Minha bicicleta poderá um dia fornecer para quem interrogá-la informações sobre o lazer da burguesia em meados do século XX, sobre a estatura média dos franceses à época, sobre as técnicas empregadas para a construção mecânica, sobre o estado da rede de estradas ou sobre as repercussões da crise do petróleo (Meyriat 1981, 52, tradução nossa).

Essa condição não invalida a compreensão de que a função primária de um objeto pode ter sido outra (o que ocorre na maior parte das vezes). Uma bicicleta tem como função 
original servir como meio de transporte, enquanto a função das roupas de camponeses do século XVII é, em primeiro lugar, proteger seus corpos. Na distinção estabelecida entre documentos por intenção e por atribuição é essencial distinguir os "objetos que são destinados desde sua origem a comunicar a informação, como os cartazes e as fitas magnéticas, e os que são encarregadas de cumprir esse papel posteriormente ou subsidiariamente" (Meyriat 1981, 52, tradução nossa).

\section{Considerações Finais}

A contribuição de Paul Otlet para a reflexão sobre o conceito de documento ultrapassa sua obra. Embora seu principal interesse tenha sido o escrito - o que o levou a conceber um modelo ampliado de documento que denominou "livro universal" - sua obra inspirou autores que lhe seguiram, a começar por Suzanne Briet (1951). A partir da década de 1980, Otlet e Briet foram retomados por inúmeros autores, dentre os quais destacamos Jean Meyriat, José Lopes Yepes e Michael Buckland, que continuaram e aprofundaram suas reflexões.

Ao propormos um exercício reflexivo sobre os conceitos de documento e musealização, sublinhamos sua potência crítica, sobretudo quando inter-relacionados e pensados em conjunto. A partir dessa perspectiva, objetos musealizados passam a ser pensados em sua dupla independência em relação ao tempo, o que lhes permite ser conservados, transportados e reproduzidos (cf. Escarpit 1976); como substitutos do livro passíveis de ser recuperados concretamente (cf. Otlet 1934); documentos primários geradores de novos documentos em um ciclo documental complexo (cf. Briet 1951); portadores de informação potencialmente transmissíveis no espaço e no tempo (cf. Lopes Yepes 1997); documentos por atribuição, produtos da vontade de ser informado (cf. Meyriat 1981).

Pensar o conceito de musealização, entretanto, equivale a estabelecer seus contornos, lembrando que tal operação põe em jogo as fronteiras do próprio Museu. Para ter alguma utilidade, um conceito deve necessariamente estabelecer um recorte. Nesse sentido, definir uma coisa implica antes de tudo em definir o que ela não é.

Afirmar que tudo é passível de ser transformado em documento implica em afirmar que tudo é, em princípio, passível de musealização. Cabe advertir, entretanto, que se tudo é musealizável, nem tudo é museu. Segundo Stránský $(1985,97)$, a condição de um objeto de museu é determinada pela relação objeto - sujeito, que não existem isoladamente, mas apenas como "parte de uma realidade natural e social" em processo constante de mudança. Para o autor, entender um objeto de museu simplesmente como objeto material e tridimensional implica na conclusão equivocada de que "o mundo inteiro é um museu". Como ressalta Abraham Moles (1981, 77), o museu deve operar um recorte para afirmar sua existência. Tudo é nada, ou, dito de outra forma: se tudo é museu, o que é museu? Há que haver limites, portanto, entre museu e mundo. 


\section{BIBLIOGRAFIA}

Alberti, Samuel. 2005. “Objects and the museum”. Isis 96 (4):559-571.

Baraçal, Anaildo B. 2008. “Objeto da Museologia: a via conceitual aberta por Zbynek Zbyslav Stránský”. Dissertação de Mestrado, Universidade Federal do Estado do Rio de Janeiro.

Beltrão, Jane Felipe. 2003. “Coleções Etnográficas: chave de muitas histórias”. DataGramaZero Revista de Ciência da Informação 4(3). Disponível em http://www.dgz.org.br/jun03/Art_01.htm

Briet, Suzanne. 1951. Quest-ce que la documentation? Paris: Editions Documentaires, Industrielles et Techniques.

Buckland, Michael. 1991. "Information as thing”. Journal of the American Society of Information Science, 48(9). Disponível em http://people.ischool.berkeley.edu/ buckland/thing.html

Buckland, Michael. 1997. "What is a document?" Journal of the American Society of Information Science, 42(5). Disponível em http://people.ischool.berkeley.edu/ buckland/whatdoc.html

Caballero Zoreda, Luis. 1986. “La documentación museologica”. Boletim Anabad 38(8):455-495.

Ceravolo, Suely e Maria de Fátima Tálamo. 2007. "Os museus e a representação do conhecimento: uma retrospectiva sobre a documentação do museu e o processamento da informação". (paper apresentado no 8.․ Encontro Nacional de Pesquisa em Ciência da Informação, Salvador, Bahia).

Couzinet, Viviane. 2009. "Complexidade e Documento: a hibridação das mediações nas áreas em ruptura". RECIIS - Revista Eletrônica de Comunicação Informação e Inovação em Saúde, 3(3):10-16.

Couzinet, Viviane. 2004. "Le document: leçon d'histoire, leçon de méthode". Communication et langages (140):19-29. Disponível em: http://www.persee.fr/web/revues/home/prescript/article/ colan_0336-1500_2004_num_140_1_3264

Deleuze, Gilles, e Felix Guattari. 1992. O que é Filosofia? Rio de Janeiro: Editora 34.

Dodebei, Vera Lúcia Doyle. 1997. “O sentido e o significado de documento para a memória sócial”. Tese de doutorado, Universidade Federal do Rio de Janeiro.

Escarpit, Robert. 1976. Théorie générale de l' Information et de la communication. Paris: Hachette.

Le Goff, Jacques. 2003. “Documento/monumento”. In História e memória. 5. e ed. Campinas: Editora da UNICAMP.

López Yepes, José. 1997. "Reflexiones sobre El concepto de documento ante La revolución de La informacion: um nuevo profesional del documento?" Scire 3(1):11-29.

Loureiro, Maria Lucia N. M. "Preservação in situ X ex situ: reflexões sobre um falso dilema". (apresentado no 3.․ Seminário Iberoamericano de Museologia, Madrid, España). Disponível em: http://www.siam2011.eu/wp-content/uploads/2011/10/Maria-Lucia-de-Niemeyer-ponenciaDraft.pdf

Lund, Niels W. 2009.“Document Theory”. ARIST, 43(1):1-55.

Maroevic, Ivo. 1998. Introduction to Museology: The European Approach. München: Verlag. 
Maroevic, Ivo. 2004. “The museum message: between the document and the information". In Museum, media, message, ed. E. Hooper-Greenhill. London: Routledge.

Meneses, Ulpiano Bezerra de. 1992. “A exposição museológica: reflexões sobre pontos críticos na prática contemporânea”. Ciências em Museus, 4:103-120.

Meneses, Ulpiano Bezerra de. 1998. "Memória e cultura material: documentos pessoais no espaço público”. Estudos Históricos, Rio de Janeiro, 11(21):89-104.

Mensch, Peter van. 1992. "Towards a methodology of museology". PhD Thesis, University of Zagreb.

Metzger, Jean-Paul. 2006. "L'information-documentation". In Sciences de l'information et de la communication - Objets, savoirs, discipline, ed. S. Olivesi et al. Grenoble: Presses Universitaires de Grénoble.

Meyriat, Jean. 1981. "Document, documentation, documentologie". Schéma et Schématisation, (14): 51-63.

Moles, Abraham. 1981. Teoria dos Objetos: Rio de Janeiro: Tempo Brasileiro.

Murguia, Eduardo. 2011. "Percepções e aproximações do documento na Historiografia, Documentação e Ciência da Informação". Revista de Ciência da Informação e Documentação, 2

(2):42-53.

Ortega, Cristina D. e Lara M. L. G. 2009. “A noção de documento: de Otlet aos dias de hoje”. (paper apresentado no IX Congreso ISKO-España, Valencia).

Otlet, Paul. 1934. Traité de Documentation: Le livre sur le livre. Bruxelles: Mundaneum.

Pearce, Susan. 1992. Museums, objects and collections. Washington: Smithsonian Institution Press.

Pomian, Krzysztof. 1984. “Colecção”. In Enciclopedia Einaudi. Vol. 1. Lisboa: Imprensa Nacional, Casa da Moeda.

Rabello, Rodrigo. 2009. "A face oculta do documento: tradição e inovação no limiar da Ciência da Informação”. Tese de Doutorado, Universidade Estadual Paulista Júlio de Mesquita Filho.

Schreiner, Klaus. 1980. “Museology: science or just practical museum work?”. Museological Working Papers, (1):39-41.

Smit, Johanna. 2008. "A Documentação e suas diversas abordagens". In Documentação em Museus, ed. M. Granato, C. P. Santos e M. L. N. Loureiro. Rio de Janeiro: Museu de Astronomia e Ciências Afins.

Stránský, Zbynek Z. 1985. “Originals versus substitutes”. ICOFOM Study Series, 9: 95-102.

Stránský, Zbynek Z. 1987. “Symposium Museologie and Museums”. ICOFOM Study Series, 12:287-298.

\section{NOTAS}

1. Para a realização deste trabalho os autores receberam o apoio do Conselho Nacional de Desenvolvimento Científico e Tecnológico - CNPq (Brasil).

2. União Francesa de Organismos de Documentação.

3. Contribuição de Stránský ao Simpósio de Museologia realizado em Brno, no ano de 1965 (Cf. Mensch 1992). 
4. Definição dada em 1974, em uma publicação referente ao curso de Museologia na Universidade Jan E. Purkinje, em Brno (Cf. Mensch 1992).

5. No original, "museality" ou "musealité" (Stránský 1985).

6. No original em inglês "the museum character of things" e, em francês "caractère muséal" (Stránsky 1987, 289, 295).

7. Essa operação ocorre não apenas em processos de musealização ex-situ (ou clássica, baseada no colecionismo), mas também na musealização in-situ: espaços musealizados e seus elementos são igualmente imbuídos de uma função documental.

\section{RESUMOS}

O texto aborda a musealização como processo (ou conjunto de processos) por meio dos quais alguns objetos são privados de sua função original e, uma vez revestidos de novos significados, adquirem a função de documento. Enfatiza o caráter informacional do processo de musealização e apresenta reflexões em torno da noção de documento ao longo do século XX, destacando a ampliação do conceito para além do escrito e a contribuição pioneira de Paul Otlet.

The text addresses musealisation as a process (or set of processes) through which some objects are deprived of their original function and, after gaining new meanings, acquire the role of document. The text emphasizes the informational nature of the processes of musealisation and presents reflections on the notion of the document throughout the twentieth century, highlighting the expansion of the concept beyond the writing and pioneering contribution of Paul Otlet.

\section{ÍNDICE}

Palavras-chave: musealização, documento, coleção, Paul otlet

Keywords: musealisation, collection, Paul Otlet

\section{AUTORES}

\section{MARIA LUCIA DE NIEMEYER MATHEUS LOUREIRO}

Possui graduação em Museologia pelo Museu Histórico Nacional - atual Escola de Museologia da Universidade Federal do Estado do Rio de Janeiro (1976) -, mestrado (1998) e doutorado (2003) em Ciência da Informação pelo IBICT - Instituto Brasileiro de Informação em Ciência e Tecnologia/ UFRJ - Universidade Federal do Rio de Janeiro. Atua na coordenação de museologia do Museu de Astronomia e ciências Afins. Realiza pesquisas relacionadas à divulgação científica, linguagens expositivas e processos de musealização nos domínios da arte, ciência e tecnologia. marialucia@mast.br 


\section{JOSÉ MAURO MATHEUS LOUREIRO}

Possui graduação em Museologia pela Universidade Federal do Estado do Rio de Janeiro (1980), mestrado (1996) e doutorado (2000) em Ciência da Informação pela Universidade Federal do Rio de Janeiro e estágio pós-doutoral em Antropologia Social (PPGAS/MN/UFRJ). Professor associado da Universidade Federal do Estado do Rio de Janeiro. Realiza pesquisas sobre os seguintes temas: museu, informação, memória e epistemologia.jmmloureiro@gmail.com 